\title{
ДЕСТРУКТИВНОЕ ПОВЕДЕНИЕ В ПРОБЛЕМНОМ ПОЛЕ ГУМАНИТАРНОЙ НАУКИ
}

\author{
Антипова Елена Александровна 1 , \\ leno-1998@mail.ru \\ Ларионова Анастасия Вячеславовна ${ }^{2,1}$, \\ vktusur@mail.ru \\ Орлова Вера Вениаминовна², \\ vera.v.orlova@tusur.ru
}

$\mathbf{1}$ Национальный исследовательский Томский государственный университет, Россия, 634050, г. Томск, пр. Ленина, 36

2 Томский государственный университет систем управления и радиоэлектроники, Россия, 634050, г. Томск, пр. Ленина, 40

\begin{abstract}
Антипова Елена Александровна, студент факультета психологии Национального исследовательского Томского государственного университета.

Ларионова Анастасия Вячеславовна, кандидат психологических наук, доцент кафедры философии и социологии Томского государственного университета систем управления и радиоэлектроники; доцент кафедры генетической и клинической психологии факультета психологии Национального исследовательского Томского государственного университета.
\end{abstract}

Орлова Вера Вениаминовна, доктор социологических наук, профессор кафедры философии и социологии Томского государственного университета систем управления и радиоэлектроники.

В статье рассматривается проблема деструктивного поведения с позиции различных гуманитарных наук (социологии, психологии, педагогики, юриспруденции). Поднимается вопрос о типологических особенностях деструктивного поведения, развитии его новых форм проявления и классификаций. В последний год отмечается обострение нестабильности в различных сферах жизни из-за изменения режима жизнедеятельности, вызванного пандемией, что спровоцировало появление новых видов деструктивного поведения. Цель исследования - изучить современные деструктивные формы поведения человека, особенности их типологизации и имеющийся научный задел для дальнейшего изучения. Рассматриваются основные факторы, влияющие на деструктивное поведение молодежи: индивидуально-психологические особенности человека, семейная и образовательная среда, цифровое пространство, изменение режима жизнедеятельности в условиях пандемии. В результате обозначены основные направления исследования проблемы деструктивного поведения в отечественной и зарубежной психологии.

Ключевые слова: Деструктивное поведение, молодежь, типология, формы, аутодеструктивное поведение.

Рост и развитие различных видов крайних форм поведения являются результатом взаимодействия личности и среды, что обусловлено нестабильностью многих сфер жизни современного общества, с цивилизационным и мировоззренческим кризисом современности, разрушением модели идентичности человека, проблемами личностного самоопределения и ценностно-смысловых ориентаций. В последний год отмечается обострение нестабильности в различных сферах жизни из-за изменения режима жизнедеятельности, вызванного пандемией. Внимание гуманитарной науки в настоящее вре- 
мя обращено на ведущие тенденции современности - глобализацию, транзитивность, цифровизацию-виртуализацию, видимую трансформацию ценностей. Это неуклонно изменяет ландшафт жизненного мира человека - новый режим жизни и новая информация влияют на его мышление, поведение, сознание и мировоззрение, но одновременно усложняющийся и динамичный мир порождает новые деструктивные тенденции человека.

Деструктивное поведение является предметом разных областей научного гуманитарного познания, таких как философия, социология, психология, педагогика, юриспруденция, что обусловливает множество подходов к его пониманию и изучению. Основные принципы рассмотрения деструктивного поведения были заложены еще в период Античности, когда деструктивное поведение мыслителями той эпохи понималось как поведение, противоречащее этике и морали общества, как отклонение от идеала личности, как зависимое от культурных форм общественной жизни. Далее в научных исследованиях деструктивности можно выделить две группы ее анализа - как врожденного свойства с рассмотрением биологических факторов поведения (К. Лоренц, Ф. Гальтон, Ч. Ломброзо, У. Шелдон, Р. Кречмер) или как формируемого качества в процессе социализации личности под влиянием социокультурных факторов (Э. Дюркгейм, Р. Мертон, П. Уорсли, Т. Парсон, Л. С. Выготский, С.Л. Рубинштейн, А.Н. Леонтьев, В.Н. Мясищев). В психоаналитических концепциях 3. Фрейда, К.Г. Юнга, А. Адлера и Э. Фромма деструктивность рассматривается как неосознаваемый человеком мотиватор, как следствие негативного отношения человека к самому себе в структуре его основных влечений, как результат отчужденности и беспомощности, как нереализованный потенциал человека с невозможностью использовать свою энергию по назначению.

В современной гуманитарной науке нет единого определения понятия деструктивного поведения, отсутствует общепринятая стандартная интерпретация его значения, выделяется масса вариантов разграничений понятия с терминами «девиантное поведение» и «агрессивное поведение». Так, авторы М.Н. Кузнецова, Л.С. Рычкова, В.Б. Куликов, К.В. Злоказов выделяют основные отличительные признаки данного феномена. Деструктивное поведение, согласно их исследованиям, представляет собой поведение, направленное на разрушение социальных объектов и связей, причинение вреда обществу или самому себе [1-4]. По отношению к девиантному поведению оно рассматривается как отрицательный его вид, направленный непосредственно на уничтожение или преобразование какой-либо структуры. Соотношение понятий «агрессивного» и «деструктивного» поведения не имеет четких границ в науке, т. к. их проявления внешне схожи.

Недостаточная дефиниция термина деструктивного поведения приводит к многочисленным типологиям феномена, основанным на различных критериях. Классификация деструктивного поведения по цели, направленности и способам осуществления включает метаперсональное, интерперсональное, интраперсональное деструктивное поведение. В литературе встречается сходная по своему значению классификация, в которой выделяют: внешне-деструктивное (антисоциальное), косвенно-деструктивное (асоциальное) и аутодеструктивное (диссоциальное) поведение $[1,5]$. Данные классификации объединяют принцип направленности деструктивного поведения - вовне (на конкретные личности, группы, общество в целом, его ценности) и внутрь, то есть на самого человека, характер же самого поведения, его средства и способы осуществления действий могут иметь большое количество разновидностей в зависимости от конкретного случая. 
В исследованиях новых видов проявления деструктивного поведения рассматривается трансформация не только самих способов реализации такого поведения, но и используемых средств и среды, в которой оно реализуется и на которую направлено, а также целей $[2,6,7]$. Выделяются следующие формы деструктивного поведения, направленные вовне, в зависимости от среды, как моббинг, в различного типа организациях проявляющийся в виде психологического воздействия на сотрудников с целью принижения профессиональной компетенции и унижения [7]; буллинг в школьной среде; экстремизм и терроризм в общественной среде как одна из крайних форм проявления деструктивного поведения, направленного против определенных групп общества; вандализм, направленный не только на разрушение общественных ценностей, но и информационной среды (информационный вандализм) [2].

Современная цифровизация общества способствует усилению деструктивных практик личности. А.Е. Скачок отмечает, что все большую роль в формировании деструктивного и агрессивного поведения играют социальные сети [8]. В социальных сетях распространяется большое количество информации, и очень часто она может иметь скрытый деструктивный характер, формируя определённый информационный фон, способствующий возникновению различных деструктивных мыслей и идей и приводящий к отклонениям в поведении. Вовлечение все большего числа пользователей в компьютерные и интернет-игры, где можно реализовывать свои деструктивные мотивы в общении и взаимодействии с другими людьми или элементами игрового мира, также накладывает отпечаток на развитие деструктивности [9]. Это приводит к появлению и развитию в Интернете исконно цифровых видов преступлений, таких как кибертерроризм и кибербуллинг [6], возникают различные «группы смерти», игры и элементы контента, призывающие пользователей совершать аутодеструктивные действия и склоняющие их к насилию и разрушению существующих норм и правил общества или отдельных его элементов [10]. Перевод в дистанционный формат большинство сфер жизнедеятельности (обучение, работа, быт) вызвал рост цифровых преступлений. По данным Главного информационно-аналитического центра МВД России, с января по октябрь 2020 года зафиксировано на 75,1 \% больше преступлений, совершенных с использованием информационно-телекоммуникационных технологий по сравнению с аналогичным периодом в 2019 г. [11].

Анализ работ отечественных и зарубежных исследователей, посвященных проблематике деструктивного поведения, выявил еще один важный аспект данной тематики - аутодеструктивные (саморазрушающие) тенденции личности. Феномен аутодеструктивного поведения, направленного на причинение вреда собственному физическому или психическому здоровью, относят к интерпесональным видам деструктивного поведения (направлено внутрь) (Н.А. Польская, Н.В. Власова, Н.Н. Васягина, Н.Б. Сычёва) $[12,13]$. Оно проявляется в форме различных действий, приносящих вред индивиду, - это суицидальные тенденции и самоповреждающие действия, употребление алкоголя и наркотиков, расстройства пищевого поведения, сексуальная распущенность и т. д. По данным Н.Б. Сычёвой, для 80 \% подростков свойственен один и более вид аутодеструктивного поведения [14]. Большое значение имеет то, что долгое время оно может протекать незаметно для окружающих, что повышает риск для здоровья человека и может приводить к суицидальным попыткам. По данным сайта статистики Статдата, в России наблюдается снижение количества суицидов в 2019 г. по сравнению с 2018 г. на 1176 человек, в том числе и среди несовершеннолетних [15]. Но уже сейчас понятно, что новый режим жизни наложил отпечаток на психологическое и психическое состояние человека, последствия которого предстоит изучать еще несколько лет. 
По данным Научного медицинского исследовательского центра здоровья детей Министерства здравоохранения РФ, самоизоляция и дистанционное обучения сказались на психическом здоровье 83,8 \% российских школьников. Более 50 \% учащихся негативно отреагировали на режим самоизоляции $[16,17]$.

Ряд отечественных авторов особое внимание уделяют проблеме агрессивного и аутоагрессивного поведения подростков и молодёжи, а также его профилактике и коррекции $[13,18-22]$. Актуальность данной проблемы исследователи обосновывают возрастными особенностями этой группы и особой их сензитивностью к формированию различных деструкций. Несмотря на серьезные продвижения в изучении данной проблемы и разработке различных коррекционных и профилактических программ, нестабильность общества, политические и социальные проблемы провоцируют возникновение деструктивного поведения. К основным факторам возникновения и развития деструктивного поведения детей и молодежи относят семейную и образовательную среду и индивидуально-психологические особенности человека. Эти же факторы являются основными в профилактике и коррекции деструктивного поведения детей и молодежи [23].

Развивая тему подростковой деструкции, некоторые авторы показывают особую роль моделей семейного воспитания в формировании деструктивного поведения ребенка $[24,25]$. Традиционно выделяются несколько форм негативного влияния семьи на формирование личности детей и молодежи: 1) антиобщественные ценности в семье и целенаправленное формирование их у детей; 2) внушение ребенку негативных стандартов поведения как образа жизни (алкоголизм, наркомания, проституция, преступная деятельность и т. д.); 3) бесконтрольность формирования личности ребенка со стороны семьи; 4) эмоционально-конфликтные отношения в семье [26]. Например, A.M. Monteleone, V. Ruzzi, G. Patriciello определили, что высокий уровень контроля со стороны матери связан с появления расстройств пищевого поведения у ребенка [27]. Исследователями M. Schmoeger, M. Deckert, P. Wagner и др. была обнаружена зависимость отношений с родителями и особенностей восприятия качества отношений с интимным партнером среди молодежи [28].

Следующий фактор влияния - образовательная среда. В образовательном учреждении происходит формирование коммуникативных навыков, социализация и поиск значимой группы. В школах подростки проводят большое количество времени, усваивая знания, нормы, правила поведения, что отражается на их поведении и мировоззрении. Среди форм деструктивного поведения в школе выделяются агрессивные действия, разрушение школьного имущества, нарушение общественного порядка, противодействие авторитетам и саморазрушение [19]. Целями совершения этих действий могут выступать различные детерминанты, такие как мотивы самоутверждения в группе и в своих глазах, желание избавиться от чувства тревоги посредством ее деструктивной разрядки или мотивы реализации реакции на негативное воздействие [29].

Причиной негативного воздействия на детей образовательной среды, по мнению Л.А. Липской (2019), является невысокая эффективность осуществления социализирующих функций школой в качестве основного социального института, оказывающего влияние на не только умственное, но и духовно-нравственное воспитание ребенка [21]. Различные формы негативного психологического воздействия учителей на детей, конфликтные межличностные отношения учеников - все это может уходить из поля внимания взрослых, формализуя процесс образования и превращая его в исключительно передачу знаний по предметам. 
Следующий фактор деструктивного поведения - индивидуально-психологические особенности личности детей и молодежи. К ним относят личностные предпосылки формирования отклоняющегося поведения, такие как высокий показатель тревожности, низкая самооценка, агрессивность, психологическая неустойчивость, низкий уровень правовой осведомленности и т. д. $[8,21]$. Среди зарубежных работ особую группу составляют исследования, направленные на изучение взаимосвязи отклоняющихся форм поведения (в том числе деструктивных) и психических заболеваний [30, 31], а также те, которые включают в систему факторов генетические детерминанты, отклонения в когнитивном и эмоциональном развитии, различные личностные характеристики и связанные с темпераментом качества личности [32-34]. Особый интерес представляют рассмотренные зарубежными авторами (L.N. Natsun, I.N. Razvarina, E.O. Smoleva) биографические и макросоциальные факторы (физически здоровые дети часто живут в неблагоприятных условиях жизни, препятствующих адекватной социализации), оказывающие влияние на формирование деструктивных тенденций у детей. Авторы также обращают внимание на связь психического состояния здоровья детей, экономики стран и репродуктивного здоровья нации. Согласно их исследованиям, ухудшение психического здоровья детей, появление рискованного и деструктивного поведения приводят к снижению человеческого потенциала, что выявляет необходимость изучения и профилактики данного явления [33].

В зарубежных исследованиях актуальным является изучение деструктивного поведения взрослых и пожилых людей (H. Choi, L.B. Kenneally). Авторы подчеркивают, что вмешательство в процесс формирования тенденций деструктивного поведения возможен в любом возрасте и это вмешательство необходимо, так как по результатам исследований примерно у 19 \% пожилых людей обнаруживаются агрессивные формы поведения, связанные с различными факторами, включая медицинские (деменция и т. д.) и социальные (социальная вовлеченность) $[32,35]$. Данные исследований показывают, что группой риска возникновения деструктивного поведения могу являться не только подростки и дети, но и люди разных возрастных групп, поэтому выявление предрасположенности к его возникновению должно базироваться на изучении взаимовлияния личностных особенностей и факторов окружающей среды, к которой адаптируется человек на протяжении своей жизни.

В современном поле исследований обнаруживается недостаток: комплексных исследований деструктивного поведения, рассматривающих его как с биологической точки зрения, так и с социальной; в расширении комплекса причин и факторов, приводящих к формированию деструкций во всех возрастных группах; новых современных методов ранней диагностики склонности личности к агрессивным и насильственным формам поведения; профилактических и психокоррекционных мер.

Анализ отечественных и зарубежных исследований (прикладного и специализированного характера) по проблеме деструктивного поведения человека показал необходимость: 1) обстоятельной систематизации, объединения разнонаправленных изысканий в единую научную парадигму; 2) разработки комплексного подхода к изучению феномена деструкции, деструктивных тенденций и деструктивных практик. Такой подход требует совместных междисциплинарных усилий, учитывающих все многообразие условий, факторов и предикторов деструктивного поведения человека, его профилактики и коррекции. 


\section{СПИСОК ЛИТЕРАТУРЫ}

1. Злоказов К.В. Деструктивное поведение в различных контекстах его проявления // Вестник Удмуртского университета. Серия «Философия. Психология. Педагогика». - 2016. - Т. 26 (4). - С. 67-73.

2. Кружкова О.В., Девятковская И.В. Организационный вандализм: к проблеме деструктивного поведения персонала // Сибирский психологический журнал. - 2017. - № 63. - С. 150-169.

3. Кузнецова М.Н. Обзор теоретических аспектов деструктивного поведения личности // Ученые записки университета им. П.Ф. Лесгафта. - 2018. - № 2 (156). - С. 340-343.

4. Рычкова Л.С., Кузнецова М.Н. Подходы к пониманию деструктивного поведения в зарубежной и отечественной психологии // Вестник Челябинского государственного педагогического университета. - 2018. - № 4. - С. 172-180.

5. Клейберг Ю.А. Типология деструктивного поведения // Вестник Краснодарского университета МВД России. - 2008. - № 1. - С. 130-135.

6. Суркова И.Ю., Зеленский П.А., Алексеевская Я.И. Кибербуллинг в пространстве интернет-коммуникаций как форма деструктивной активности молодежи // Парадигма. - 2019. - № 2. - С. 72-81.

7. Моббинг как вид деструктивного поведения в образовательных организациях высшего образования / Л.В. Шелехова, А.В. Нагоев, 3.У. Блягоз, В.А. Тешев, К.А. Глебова // Мир науки. - 2016. - Т. 4, 3. С. 1-9.

8. Скачок А.Е. Факторы деструктивно-агрессивного поведения современного подростка и их тенденции // Психологические науки: теория и практика: материалы III Международной научной конференции. - М.: Буки-Веди, 2015. - С. 31-34.

9. Луговая О.М., Черникова И.В. Компьютерно-игровая зависимость молодежи: факторы возникновения и особенности профилактики // Проблемы современного педагогического образования. -2018. - № 60-3. - С. 440-443.

10. Васкэ Е.В., Горюнова О.И. Психолого-правовой анализ деструктивных проявлений в сети Интернет // Вестник Нижегородского университета им. Н.И. Лобачевского. - 2018. - № 6. - С. 104-110.

11. Состояние преступности в России за январь-октябрь 2020 года // Министерство внутренних дел РФ. URL: https://xn--b1aew.xn--p1ai/reports/item/21933965/ (дата обращения 21.11.2020).

12. Васягина Н.Н., Сычёва Н.Б. Особенности саморазрушающего поведения обучающихся // Педагогическое образование в России. - 2019. - № 1. - С. 93-99.

13. Польская Н.А., Власова Н.В. Аутодеструктивное поведение в подростковом и юношеском возрасте // Консультативная психология и психотерапия. - 2015. - № 4 (88). - С. 176-190.

14. Сычева Н.Б. Типы и виды саморазрушающего поведения обучающихся // Педагогическое образование в России. - 2018. - № 3. - С. 66-72.

15. Самоубийства в России за год: статистика, количество по регионам. URL: http://www.statdata.ru/samoubijstva-v-rossii (дата обращения 20.11.2020).

16. Алёхин А.Н., Дубинина Е.А. Пандемия: клиникопсихологический аспект // Артериальная гипертензия. -2020 . - № 26 (3). - С. 312-316.

17. Корытова Г.С. Аутоагрессивное поведение обучающихся в период пандемии коронавирусной инфекции и самоизоляции // Академический журнал Западной Сибири. - 2020. - Т. 16, № 3 (86). С. $26-29$.

18. Богинская Л.В. Агрессивное и аутоагрессивное поведение подростков с девиантным поведением // Вестник Таганрогского института имени А.П. Чехова. - 2016. - № 1. - С. 37-41. URL: http://www.statdata.ru/samoubijstva-v-rossii

19. Злоказов К.В. Социально-психологические предпосылки деструктивного поведения подростков в школе // Педагогическое образование в России. - 2016. - № 5. - С. 71-81.

20. Козлова Н.С., Чёрная Е. Е. Взаимосвязь эмоциональных особенностей подростков и специфики вовлеченности в социальные сети // Психологические науки: теория и практика: материалы III Международной научной конференции. - М.: Буки-Веди, 2015. - С. 39-41.

21. Липская Л.А. Факторы распространения деструктивного поведения в подростковой среде // Социум и власть. - 2019. - № 1 (75). - С. 53-59.

22. Наумова Н.В. Семья как фактор деструктивного поведения старшеклассников // Вестник Владимирского гос. ун-та им. А.Г. и Н.Г. Столетовых. Серия «Педагогические и психологические науки». 2016. - № 24 (43). - С. 155-160.

23. Аванесян Л.Р. Деструктивное поведение ребёнка как следствие деформации процесса семейного воспитания // Проблемы современного педагогического образования. - 2018. - № 58-2. - С. 4-8.

24. Реан А.А., Коновалов И.А. Индикаторы детско-родительских отношений в контексте различных социально-демографических показателей // ИТС. - 2020. - № 3 (100). - С. 433-450. 
25. Поливанова К.Н. Детство в меняющемся мире // Современная зарубежная психология. - 2016. - Т. 5 , № 2. - С. 5-10. DOI 10.17759/ jmfp.2016050201.

26. Шестакова Е.В. Косвенное формирование противоправного поведения как форма семейной десоциализации личности несовершеннолетнего // Юридическая наука и правоохранительная практика. 2017. - № 1 (39). - C. 187-191.

27. Monteleone A.M., Ruzzi V., Patriciello G. Parental bonding, childhood maltreatment and eating disorder psychopathology: an investigation of their interactions // Eating and Weight Disorders-Studies on Anorexia, Bulimia and Obesity. - 2020. - V. 25. - P. 577-589. DOI 10.1007/s40519-019-00649-0

28. Maternal bonding behavior, adult intimate relationship, and quality of life / M. Schmoeger, M. Deckert, P. Wagner // Neuropsychiatrie. - 2018. - V. 32. - Iss. 1. - P. 26-32. DOI 10.1007/s40211-017-0258-6

29. Злоказов К.В., Каппушев С.С. Представление о цели деструктивного поведения // Прикладная юридическая психология. - 2018. - № 1. - С. 93-100.

30. Bullying and childhood trauma events as predictive factors of suicidal behavior in borderline personality disorder: Preliminary findings / I. Alberdi-Paramo, M.D. Saiz-Gonzalez, M. Diaz-Marsa, J.L. CarrascoPerera // Psychiatry Research. - 2020. DOI: 10.1016/j.psychres.2019.112730

31. Self-injurious, aggressive and destructive behaviour in children with severe intellectual disability: Prevalence, service need and service receipt in the UK / L. Ruddick, L. Davies, M. Bacarese-Hamilton, C. Oliver // Research in Developmental Disabilities. - 2015. - V. 45-46. - P. 307-315.

32. Familial and social transmission of suicidal behavior in older adults / L.B. Kenneally, A. Szücs, K. Szanto, A.Y. Dombrovski // Journal of Affective Disorders. - 2019. - V. 245. - P. 589-596.

33. Natsun L.N., Razvarina I.N., Smoleva E.O. Risky destructive behavior of adolescents and conditions of its shaping // Problems of Territory's Development. - 2017. - № 1 (87). - P. 114-129.

34. Schick A., Cierpka M. Risk factors and prevention of aggressive behavior in children and adolescents // Journal for educational research online. - 2016. - V. 1. - P. 90-109.

35. Choi H., Jung Young-Il, Kim H. Factors related to aggressive behaviors among older adults in nursing homes of Korea: A cross-sectional survey study // International Journal of Nursing Studies. - 2018. V. 88. - P. 9-15.

Поступила 23.11.2020 2. 
UDC 316.624

\title{
DESTRUCTIVE BEHAVIOR IN THE PROBLEMATIC FIELD OF HUMANITIES
}

\author{
Elena A. Antipova ${ }^{1}$, \\ leno-1998@mail.ru \\ Anastasiya V. Larionova2,1, \\ vktusur@mail.ru \\ Vera V. Orlova ${ }^{2}$, \\ vera.v.orlova@tusur.ru \\ 1 National Research Tomsk State University, \\ 36, Lenin avenue, Tomsk, 634050, Russia. \\ 2 Tomsk State University of Control Systems and Radioelectronics, \\ 40, Lenin avenue, Tomsk, 634050, Russia.
}

Elena A. Antipova, student, National Research Tomsk State University.

Anastasiya V. Larionova, Cand. Sc., associate professor, National Research Tomsk State University; associate professor, Tomsk State University of Control Systems and Radioelectronics.

Vera V. Orlova, Dr. Sc., professor, Tomsk State University of Control Systems and Radioelectronic.

The article examines the problem of destructive behavior from the standpoint of various humanities (sociology, psychology, pedagogy). The question is raised about the typological features of destructive behavior, the development of its new forms of manifestation and classifications. In the last year, there has been an exacerbation of instability in various spheres of life due to a change in the mode of life caused by a pandemic. The paper considers the main factors influencing the destructive behavior of young people: individual psychological characteristics of a person, family and educational environment, digital space, changes in the mode of life in a pandemic. As a result, the main directions in the research of destructive behavior problem in domestic and foreign psychology are outlined.

Key words: Destructive behavior, youth, typology, forms, self-destructive behavior.

\section{REFERENCES}

1. Zlokazov K.V. Destruktivnoe povedenie v razlichnykh kontekstakh ego proyavleniya [Destructive behavior in various contexts of its manifestation]. Vestnik Udmurtskogo universiteta. Seriya "Filosofiya. Psikhologiya. Pedagogika», 2016, vol. 26 (4), pp. 67-73.

2. Kruzhkova O.V., Devyatkovskaya I.V. Organizatsionny vandalizm: k probleme destruktivnogo povedeniya personala [Organizational vandalism: to the problem of destructive behavior of personnel]. Sibirskiy psikhologicheskiy zhurnal, 2017, no. 63, pp. 150-169.

3. Kuznetsova M.N. Obzor teoreticheskikh aspektov destruktivnogo povedeniya lichnosti [Review of theoretical aspects of destructive personality behavior]. Uchenye zapiski universiteta im. P.F. Lesgafta, 2018, no. 2 (156), pp. 340-343.

4. Rychkova L.S., Kuznetsova M.N. Podkhody k ponimaniyu destruktivnogo povedeniya v zarubezhnoy i otechestvennoy psikhologii [Approaches to understanding destructive behavior in foreign and domestic psychology]. Vestnik Chelyabinskogo gosudarstvennogo pedagogicheskogo universiteta, 2018, no. 4, pp. 172180 . 
5. Kleyberg Yu.A. Tipologiya destruktivnogo povedeniya [Typology of destructive behavior]. Vestnik Krasnodarskogo universiteta MVD Rossii, 2008, no. 1, pp. 130-135.

6. Surkova I.Yu., Zelenskiy P.A., Alekseevskaya Ya.I. Kiberbulling v prostranstve internet-kommunikatsiy kak forma destruktivnoy aktivnosti molodezhi [Cyberbullying in the space of Internet communications as a form of destructive activity of youth]. Paradigma, 2019, no. 2, pp. 72-81.

7. Shelekhova L.V., Nagoev A.V., Blyagoz Z.U., Teshev V.A., Glebova K.A. Mobbing kak vid destruktivnogo povedeniya $\mathrm{v}$ obrazovatelnykh organizatsiyakh vysshego obrazovaniya [Mobbing as a type of destructive behavior in educational institutions of higher education]. Mir nauki, 2016, vol. 4, no. 3, pp. 1-9.

8. Skachok A.E. Faktory destruktivno-agressivnogo povedeniya sovremennogo podrostka i ikh tendentsii [Factors of destructive-aggressive behavior of a modern adolescent and their tendencies]. Psikhologicheskie nauki: teoriya i praktika. Materialy III Mezhdunarodnoy nauchnoy konferentsii [Psychological sciences: theory and practice. Proc. of the III International scientific conference]. Moscow, Buki-Vedi Publ., 2015. pp. 31-34.

9. Lugovaya O.M., Chernikova I.V. Kompyuterno-igrovaya zavisimost molodezhi: faktory vozniknoveniya i osobennosti profilaktiki [Computer-gambling addiction of youth: factors of occurrence and features of prevention]. Problemy sovremennogo pedagogicheskogo obrazovaniya, 2018, no. 60-3, pp. 440-443.

10. Vaske E.V., Goryunova O.I. Psikhologo-pravovoy analiz destruktivnykh proyavleniy v seti Internet [Psychological and legal analysis of destructive manifestations on the Internet]. Vestnik Nizhegorodskogo universiteta im. N. I. Lobachevskogo, 2018, no. 6, pp. 104-110.

11. Sostoyanie prestupnosti v Rossii za yanvar-oktyabr 2020 goda [The state of crime in Russia in JanuaryOctober 2020]. Available at: https://xn--b1aew.xn--p1ai/reports/item/21933965/ (accessed 21 November 2020).

12. Vasyagina N.N., Sycheva N.B. Osobennosti samorazrushayushchego povedeniya obuchayushchihsya [Features of self-destructive behavior of students]. Pedagogicheskoe obrazovanie v Rossii, 2019, no. 1, pp. 93-99.

13. Polskaya N.A., Vlasova N.V. Autodestruktivnoe povedenie v podrostkovom i yunosheskom vozraste [Autodestructive behavior in adolescence and adolescence]. Konsultativnaya psihologiya i psihoterapiya. 2015, no. 4 (88), pp. 176-190.

14. Sycheva N.B. Tipy i vidy samorazrushayushchego povedeniya obuchayushchihsya [Types and types of selfdestructive behavior of students]. Pedagogicheskoe obrazovanie v Rossii, 2018, no. 3, pp. 66-72.

15. Samoubiystva $v$ Rossii za god: statistika, kolichestvo po regionam [Suicides in Russia for the year statistics, number by region]. Available at: http://www.statdata.ru/samoubijstva-v-rossii (accessed 20 November 2020).

16. Alekhin A.N., Dubinina E.A. Pandemiya: klinikopsikhologicheskiy aspect [Pandemic: Clinical Psychological Aspect]. Arterialnaya gipertenziya, 2020, no. 26 (3), pp. 312-316.

17. Korytova G.S. Autoagressivnoe povedenie obuchayushchihsya v period pandemii koronavirusnoy infektsii i samoizolyatsii [Auto-aggressive behavior of students during the coronavirus pandemic and self-isolation]. Akademicheskiy zhurnal Zapadnoy Sibiri, 2020, no. 3 (86), vol. 16, pp. 26-29.

18. Boginskaya L.V. Agressivnoe i autoagressivnoe povedenie podrostkov s deviantnym povedeniem [Aggressive and auto-aggressive behavior of adolescents with deviant behavior]. Vestnik Taganrogskogo instituta imeni A.P. Chekhova, 2016, no. 1, pp. 37-41.

19. Zlokazov K.V. Sotsialno-psikhologicheskie predposylki destruktivnogo povedeniya podrostkov v shkole [Socio-psychological prerequisites for the destructive behavior of adolescents at school]. Pedagogicheskoe obrazovanie v Rossii, 2016, no. 5, pp. 71-81.

20. Kozlova N.S., Chornaya E.E. Vzaimosvyaz emotsionalnykh osobennostey podrostkov i spetsifiki vovlechennosti $\mathrm{v}$ sotsialnye seti [Relationship between the emotional characteristics of adolescents and the specifics of involvement in social networks]. Psikhologicheskie nauki: teoriya i praktika. Materialy III Mezhdunarodnoy nauchnoy konferentsii [Psychological sciences: theory and practice. Proc. of the III International scientific conference]. Moscow, Buki-Vedi Publ., 2015. pp. 39-41.

21. Lipskaya L.A. Faktory rasprostraneniya destruktivnogo povedeniya $\mathrm{v}$ podrostkovoy srede [Factors of the spread of destructive behavior in adolescents]. Sotsium i vlast, 2019, no. 1 (75), pp. 53-59.

22. Naumova N.V. Semya kak faktor destruktivnogo povedeniya starsheklassnikov [Family as a factor in destructive behavior of high school students]. Vestnik Vladimirskogo gos. un-ta im. A.G. i N.G. Stoletovykh. Seriya «Pedagogicheskie i psikhologicheskie nauki», 2016, no. 24 (43), pp. 155-160.

23. Avanesyan L.R. Destruktivnoe povedenie rebenka kak sledstvie deformatsii protsessa semeynogo vospitaniya [Destructive behavior of a child as a result of deformation of the process of family education]. Problemy sovremennogo pedagogicheskogo obrazovaniya, 2018, no. 58-2, pp. 4-8. 
24. Rean A.A., Konovalov I.A. Indikatory detsko-roditelskikh otnosheniy v kontekste razlichnykh sotsialnodemograficheskikh pokazateley [Indicators of parent-child relationships in the context of various sociodemographic indicators]. ITS, 2020, no. 3 (100), pp. 433-450.

25. Polivanova K.N. Detstvo v menyayushchemsya mire [Childhood in a changing world]. Sovremennaya zarubezhnaya psihologiya, 2016, vol. 5, no. 2, pp. 5-10. DOI: 10.17759/ jmfp.2016050201.

26. Shestakova E.V. Kosvennoe formirovanie protivopravnogo povedeniya kak forma semeynoy desotsializatsii lichnosti nesovershennoletnego [Indirect formation of illegal behavior as a form of family desocialization of a minor's personality]. Yuridicheskaya nauka i pravookhranitelnaya praktika, 2017, no. 1 (39), pp. 187-191.

27. Monteleone A.M., Ruzzi V., Patriciello G. Parental bonding, childhood maltreatment and eating disorder psychopathology: an investigation of their interactions. Eating and Weight Disorders-Studies on Anorexia, Bulimia and Obesity, 2020, vol. 25, pp. 577-589. DOI: 10.1007/s40519-019-00649-0

28. Schmoeger M., Deckert M., Wagner P. Maternal bonding behavior, adult intimate relationship, and quality of life. Neuropsychiatrie, 2018, vol. 32, Iss. 1, pp. 26-32. DOI: 10.1007/s40211-017-0258-6

29. Zlokazov K.V., Kappushev S.S. Predstavlenie o tseli destruktivnogo povedeniya [Understanding the purpose of destructive behavior]. Prikladnaya yuridicheskaya psihologiya, 2018, no. 1, pp. 93-100.

30. Alberdi-Paramo I., Saiz-Gonzalez M.D., Diaz-Marsa M., Carrasco-Perera J.L. Bullying and childhood trauma events as predictive factors of suicidal behavior in borderline personality disorder: Preliminary findings. Psychiatry Research, 2020. DOI: 10.1016/j.psychres.2019.112730

31. Ruddick L., Davies L., Bacarese-Hamilton M., Oliver C. Self-injurious, aggressive and destructive behaviour in children with severe intellectual disability: prevalence, service need and service receipt in the UK. Research in Developmental Disabilities, 2015, vol. 45-46, pp. 307-315.

32. Kenneally L.B., Szücs A., Szanto K., Dombrovski A.Y. Familial and social transmission of suicidal behavior in older adults. Journal of Affective Disorders, 2019, vol. 245, pp. 589-596.

33. Natsun L.N., Razvarina I.N., Smoleva E.O. Risky destructive behavior of adolescents and conditions of its shaping. Problems of Territory's Development, 2017, no. 1 (87), pp. 114-129.

34. Schick A., Cierpka M. Risk factors and prevention of aggressive behavior in children and adolescents. Journal for educational research online, 2016, vol. 1, pp. 90-109.

35. Choi H., Jung Young-Il, Kim H. Factors related to aggressive behaviors among older adults in nursing homes of Korea: a cross-sectional survey study. International Journal of Nursing Studies, 2018, vol. 88, pp. 9-15.

Received: 23 November 2020. 